\title{
The "daily" factors research in contemporary painting ---- take Arikha for example
}

\author{
Wangzhen
}

Zaozhuang Institute, 277100

1694885175@qq.com

Keywords: Individual daily; Arikha; Personality; Life feelings

\begin{abstract}
This paper states contemporary new figurative painter Arikha's life to illustrate the meaning of "individual daily" feature in painting. This is people's re-judgment of the existence significance of humanism after their revolutionary, devastating experience of western modern art to traditional art. The study of individual factors in painting makes us understand the significance of human personality.
\end{abstract}

\section{Introduction}

"Individual daily" in painting is a part from life and is close to life, which fully performs artists' personal feelings. It is an expression of the artist life, and closely contacts with personal and ordinary people, and even vulgar art performance. It is a record of individual emotion. "Individual daily" in painting refers to the artists' life state and creation state. The work content basically can be said to be the artist's private life records.

\section{Arikha and His Painting'S Significance}

Arikha, French contemporary representative of new figurative painting, was born in 1929. He was 81 years old before death. He experienced war in his childhood, and after youth, he got into painting domain. First in abstract painting and then turned to representational painting, which covered a layer of mysterious as colorful yarn for his life.

We can see from the domestic academic journals published that in the early 80's; scholars have been boot on the painter. Entering the 90's, a comprehensive study began, and the number of academic papers also has a great increase. But these papers mostly analyze from his life experience and form sense of painting. Though the painting subjects mostly come from the analysis of records of living environment, "daily" concept is never put forward and the key is painting composition's form feeling. This was caused by domestic academic thoughts at that time. Of course, the content author proposed here is also affected by today's thoughts.

Pop art was popular in the 60's of last century. In the 80's, the western painting art started from abstract, performance, concepts, popular to a new study of figurative painting. The return of concrete image in painting is the expression need of theme content, and from that point it reflects the universal art pursuit significance and return subject consciousness. In contemporary painting, figurative painting is no longer a certain description of fixed image. It has more directional meanings. First, image metaphor and symbol of polysemy; second, the objective description of life, of course the objective here is not absolute objective without any thing attached to natural world, but the creation subject obeys his feelings "real". These two points are important differences between traditional realistic painting and contemporary representational painting. In this paper, the analysis of "individual daily" is based on these characteristics.

This paper states contemporary new figurative painter Arikha's life to illustrate the meaning of "individual daily" feature in painting. But from the study of art history (including various periods of ancient, modern and contemporary), it is found that in art history, there is not "individual daily painting" such school or classified concept. The author has no intention to define it, and just talk about my understanding of his works from another angle. 
Arikha earned his early fame with abstract painting, but in the wave of modern art, he kept the qualities of an artist - does art creation with their own independent thoughts, the with their unique aesthetic interpretation the natural shape of the world, identifies an expanding and endless painting language way from distinctive eyes.

Avigdor Arikha is Arikha's full name, but most people don't know the father's surname is not Arikha, but Da lu's, it means very long in Slavic language. Avigdor was born in a Jewish family in the countryside near the principality of Habsburg. His grandparents once went to Russia at the beginning of the 19th century, but did not settle down in there but then soon settled in Austria. Da lu's the surname going with avigdor through his entire childhood, until he went to the Palestinians, he changed the surname "Arikha", which later made him famous. The surname is actually a Hebrew, and Arikha did not translate it. Born in the early 19th century, he did not escape the baptism of war. His Jewish identity and environment made his early life more volatile than ordinary people in the war. Constant migration became his life. He had no attachment feeling for the places his lived, and had special feelings for places which had positive impact on his life, especially Paris, New York, London and Jerusalem. Arikha loved art since childhood, but did not get father's support. Of course, in the war and own the identity of Jews, his biggest problem is survival. Arikha went into the camp, and was rescued luckily. He not only studied in Jerusalem fine art colleges, also studied in national higher art school in Paris. These life experiences enriched his life and at the same time made him learn early independence.

Paris was the place where Arikha became famous. Abstract painting was popular in 1950's. Young Arikha was studying painting, and he didn't think too much and just entered abstract painting creation and won great success. But on the way of art, Arikha was not satisfied with the immediate success but constantly reflected himself, and his art. 60's was the time when Arikha abstract art became most successful and his art began shift. Arikha's painting language shifted from abstract to concrete. This shift was commented being influenced by Caravaggio and 17th century Italian painting, but as an artist in mature and successful art fashion, how could he casually being swayed by traditional paintings? According to Arikha's artistic concept, abstract modern painting is only repeating the same form, making people very tired. So he wanted to return to the realistic way, and observe and perform familiar people's life. He had this kind of idea, in my opinion is because of his spiritual needs to a large extent. That is his abstract art expression of "collective concept" in the long-term. It is autocratic resistance, an artist's re-know of life and himself. But this is not understood by all people. Most comments of his works still stay on the level of painting techniques and forms. Although sometimes someone may beat about the bush to focus "routine", it has always been neglected.

The analysis of western fine arts and Chinese domestic arts comment on Arikha's figurative paintings mostly part from its personal painting, which is fusion of free and realistic languages. As China's domestic academic journals articles made comments on Arikha's painting "Lova lay down" comments: "from the form, the picture has a floating and disorientation. A black spot on right angle and Lova's dark hair and clothes, and the cutting effect the incomplete hand formed made the whole picture extremely abstract.” From it, we can see the artist's early abstract painting experience. Another analysis of the painting"a black shawl naked": "The shape and visual effect of the graphics are very outstanding. The woman in the picture extends hands and strides feet. This not only divides the screen into many geometry block areas, but causes a kind of tension and stimulation reactions to people's vision. A narrow piece of mirror in front of a human body reflects the front part of the human body, which performs between global and local. The partial in the mirror just makes a visual point. This graphic appears to be a kind of new art concept, or hints of some regularity in painting."

Introduction of the painter's life shows artists' twists and turns in life. War and death were full in Arikha's early years, and the influence of the artist was extremely huge. Perhaps artists' love for painting at first is from the instinct to praise this world, but with painful experiences in life, this world's imperfect is revealed. In works, pure praise has become no longer practical; The creation of abstract painting may not be the purpose of the painter, but as a person, thought always becomes mature in learning and imitating. After the ups and downs of life and art, Arikha thought about the 
meaning of life, and the purpose of art. He finally chose the realistic painting language to create, and told what's in his mind through his works.

We can appreciate Arikha's many works in the 90's. As I said before, Arikha's painting is not simple to show objective, but through the picture ambiance makes everything in the picture display from viewer's heart, which is also resonance with the viewer from spiritual level. Viewing his works can make the viewer's walk into his own heart. The work is not a simple picture but a stretching toward reality space. The scene is like telling the story of the space, an performing their lives. Works reflect more public imagination got from common visual experience, that is to say scenery portray gets resonate with all men based on common sense, and achieves the height of meaning in form. We can see the wall in Arikha's picture is telling something in micro voice. That sole red umbrella, as if melancholy girl is lost and is waiting for the arrival of someone. There is no open space in the frame but drew the ideas of the viewer to distant places. Everything is so ordinary but deep. Arikha's paintings are constantly around himself and his closest life. His paintings record his own life, record their surroundings, and express the feelings at the moment of life.

Leonardo Da Vinci's "Mona Lisa" in renaissance, her smile brought us the enlightenment of humanistic. Under the guidance of humanistic care, humans get out of religious superstition, and are not controlled by god. Finally people begin to taste the joy of the existence of individual life, but this is only enlightenment. Human's questioning of self-significance is in the development of human beings. As the changes of the era and the development of science and technology, human beings' natural and scientific common perceptual experience make us lost in the seemingly absolute material world in the nearly hundred years of exploration. In relatively objective circumstances, we saw ourselves, but in the whole world we once again get lost. Duchamp perhaps gave us a beginning. His "Mona Lisa with beard" reveals his rebellion and witty and guides us to think about the other meanings of life. Duchamp's art destroyed the seriousness of art, but has reached to our shock and stimulation. He lets us realize the importance of individual character again, but fails to open the pursuit of human personality, which makes us understand the true meaning of self.

In the transition from the 1960's abstract painting to realistic painting so far, Arikha's painting gets personality characteristics of imagination and thinking abstract language beyond the real world object of pure image through previous experience. That makes his painting a bridge between the objective world and himself. Arikha knew the importance of personality, so he gave up abstract art which only repeats its form. Although he succeeded in abstract painting, this does not hinder him to the road of life. In the first eight years of transformation, he did constant sketch training. To Arikha, it is not just a kind of training in painting techniques, and more about ontology personality thinking. This is the experience and reflection of human beings since Renaissance art culture.

It can be said that human found the importance of individual is the result of Leonardo Da Vinci in Renaissance. The results brought first awakening of humanism, and it let human understand the importance of their own feeling. Arikha, with his painting art bring to us questioning and reflection of the history of western society for hundreds of years. It is a re-judge of the point of modern humanism thoughts after nearly a century's western modern art's revolutionary to the traditional art, a devastating experience. For contemporary humanism, Arikha's painting urges us to see the significance of the significance of human personality existence. Implications for human personality nature and question and inquiry for the past culture today has become a must problem to face. Arikha gives us a new humanistic meaning of the era from an artist's keen and accurate insight. We begin to focus on this important stage of the development of human culture. This is also a main feature of contemporary world culture and art. This common value reflection is because this is not a flash in the pan and grandstands some kind of artistic style. It is not hidden pseudo culture under the so-called criticism and reflection of "claim"; This is the painter's public move of his final touches, and is about meditation and introspection of individual life.

\section{The Meaning of "Daily" Factors in The Painting ---- Artist, Aesthetic Study}


From the point of view of research on artists, “daily” content study can best embody the artist's growth course. At this point, we can see from painter Arikha's analysis, that if Arikha always adheres to the abstract expressionism in the creative expression, we will not be intuitive to research deeply his state from his works.

From aesthetic value, the factors of daily conform to the overall value of contemporary trends ---the regression of humanism, and rethink of the person's value and significance. For anyone's research may be less in-depth than their own research, to awaken the numbness of the whole society, the first thing to do is to have a clear head and a clear cognition of the world. Painting's constant effect is human spirit comfort. In the context of contemporary fusion of all kinds of big relations, almost everyone highlights his instinct to avoid being submerged by times. And the meaning of "daily" on this level has important significance for artists.

\section{References}

[1]Vincent Van Gogh. Hirano. Dear Theo [M]: Hainan publishing company, 2001.

[2] Jiang Chengqing. Chinese Painting Spirit [M]. Gansu: Gansu People's Fine Arts Publishing House, 2008

[3] Liu Weidong. The meaning of the image - Chinese art history research corpus [M] : Sichuan: Sichuan Fine Arts Publishing House. 2006

[4] Liu Xiaochun. Disintegration and reconstruction - Chinese contemporary art [M] Jiangsu: Jiangsu Fine Arts Publishing House. 1986

[5] He Wanli, Forever front - the reflection and criticism of Chinese modern art [M] Henan: Zhengzhou University Press. 2003 